نوري: تأثير تغير المحتوى الرطوبي في بعض خصائص القوة لصخور الحجر الرملي في مدينة الموصل

$$
\text { ثأثنز تثغير المحتوى الرطوبي في بعض خصائص القوة لصخور الحجر الرملي في مدينة }
$$

الخلاصة

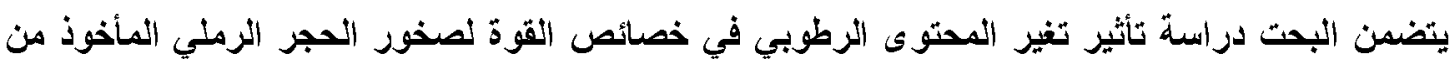

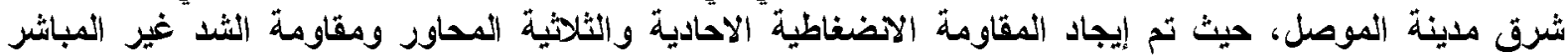

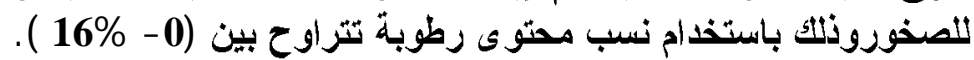

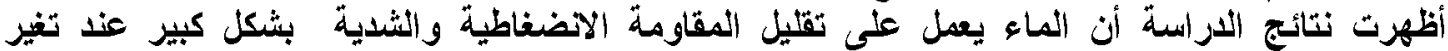

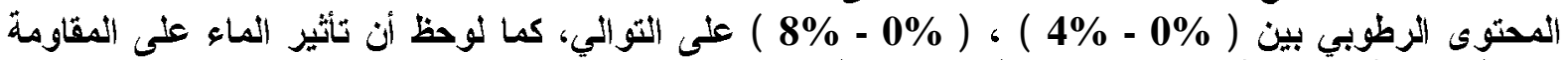
الشدية يكون أكبر من تأثيره على المقاومة الأضغاطية.

\title{
Effect of Moisture Content on Some of the Strength Characteristics of Sandstone Rock in Mosul City
}

\author{
Thamer Mohammad Noori \\ Assis. Prof. \\ Mohannad Ghanem \\ Assis. Lecturer \\ Civil Engineering department / College of Engineering - Mosul University
}

\begin{abstract}
An attempt has been made to study the effect of moisture content variation on the strength characteristics of sandstone rock selected from east of Mosul city center. Both compressive and indirect tensile strengths of the rock were determined.The obtained results indicated that the water has a considerable effects on both the compressive and tensile strengths. Higher reduction in the compressive and tensile strength were observed when the moisture content percent was between $(0 \%-4 \%)$ and $(0 \%-8 \%)$ respectively.The results also indicated that the effect of moisture content on tensile strength is greater than it's effect on compressive strength.
\end{abstract}




\section{1. المقدمة}

تعنبر صخور الحجر الرملي من الصخور الثنائعة الانتشار في المنطقة الثمالية من العراق وتتو اجد أحيانا بشكل قريب من سطح الأرض حيث يمكن أن تستخدم كأسس للأبنية أو تكون متعرضة لجزء من حمل المنشأ المقام عليها في حالة كونها بعيدة عن السطح . تصنف الصخور الزملية كصخور رسوبية ميكانيكية حيث تتكون من حبييات

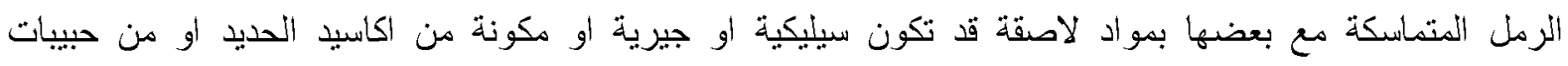

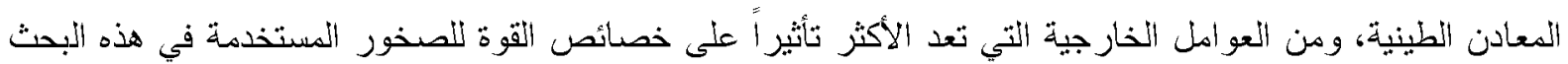

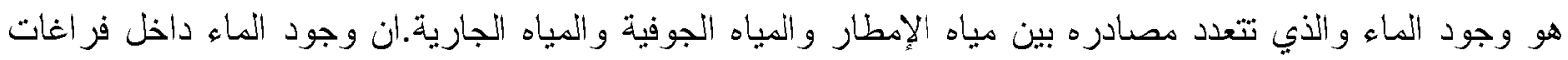

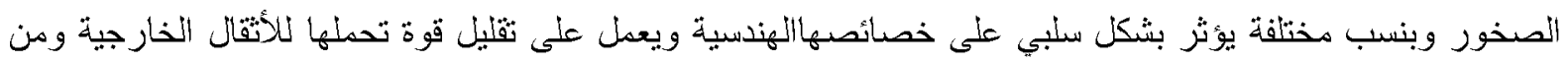
الضروري التعرف على مقدار النقصان الحاصل في القوة لضرورة ذلك في أعداد التصاميم التهنسية للمهندس المدني . أخُذتْ نماذج صخور الحجر الرملي من منطقة حي الاتتصار التي تبعد ( 8 كم شرق مدينة الموصل)، وتمتاز

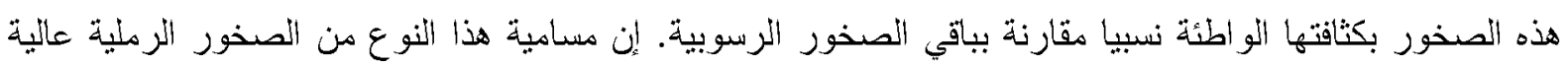

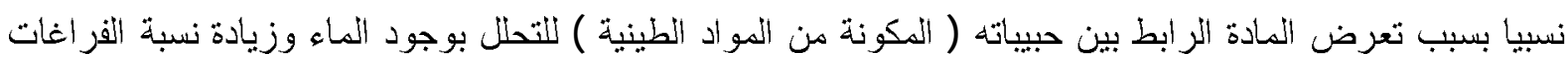
بين الجزيآت.

تضمن البحث دراسة نأثثر تغير المحتوى الرطوبي في بعض خصائص القوة والتثوه في صخور الحجر

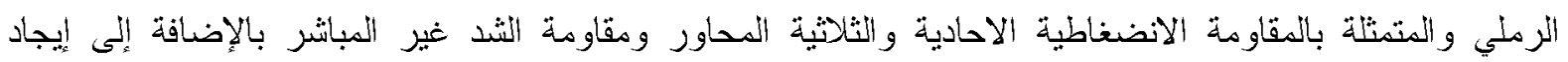

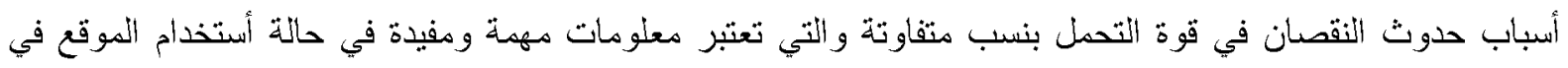

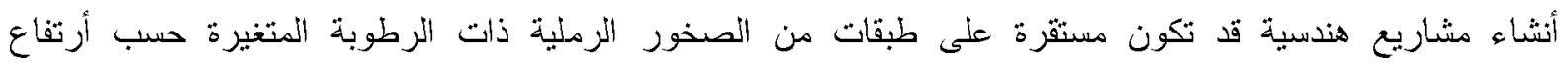
و انخفاض مستوى الماء الجوفي فيها.

قام عدة باحثين بدر اسة تأثثر تغير المحتوى الرطوبي للصخور على خصائص المقاومة وذلك لعدة أنو اع من

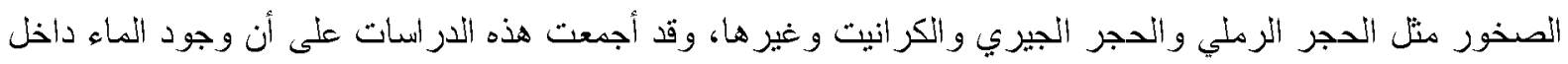

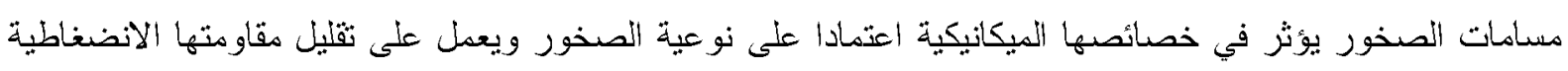
و الثدية.

وجد الباحثان (Dube and Singh, 1972) (15]أن تغير المحتوى الرطوبي من الحالة الجافة إلى الحالة الرطبة لخمسة أُواع من الصخور الترملية يعمل على تقليل مقاومة الثند بنسبة تتراوح بين ( $11 \%$ - 48\% ) وأن

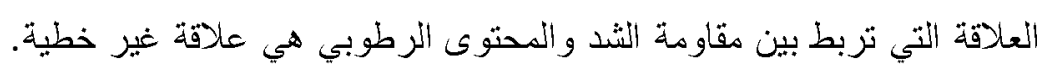

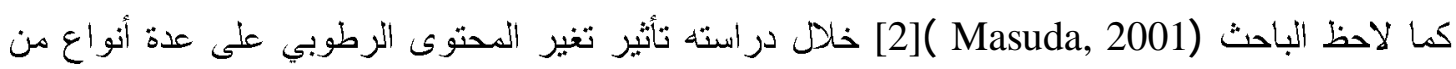
صخور الحجر الزملي أن ( $90 \%$ ) من مقاومة الانضغاط غير المحصور تفقد عند زيادة نسبة التشبع من ( 0\% ) ويكون النقصان طفيفا بعد هذه النسبة.

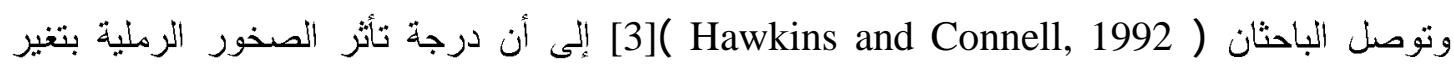

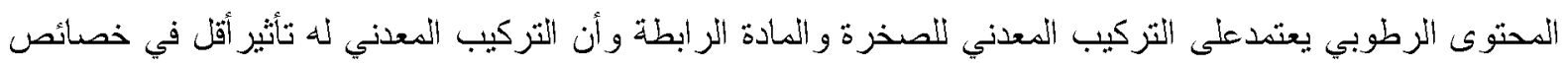

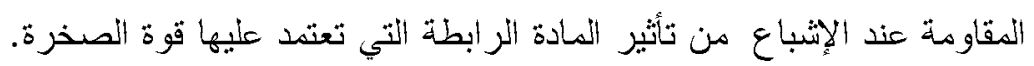


نوري: تأثير تغير المحتوى الرظويي في بعض خصائص القوة لصخور الحجر الزملي في مدينة الموصل

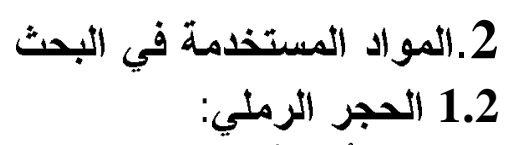

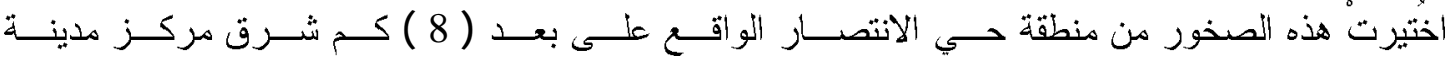

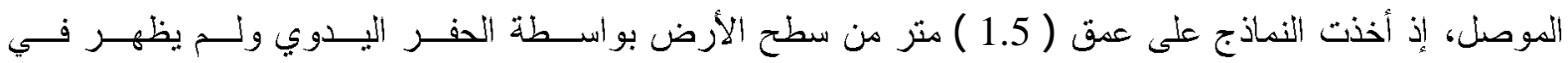

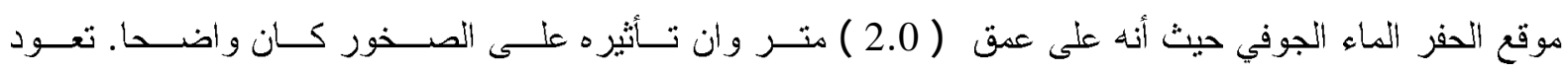

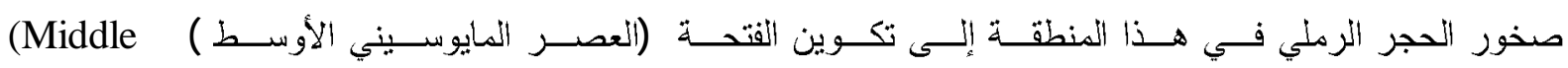

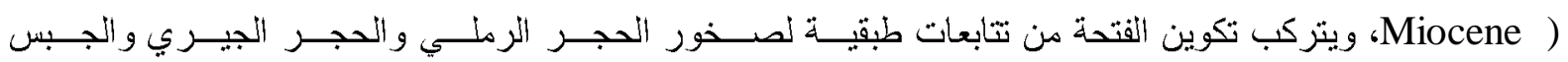
و المارل بسمك مختلف [4].

أجريت الفحوصات الفيزيائية على الحجر الرملي اعتمادا على المواصفات العالمية للصخور (ISMR) [5] وجميع النتائج موضدة في الجدول رقم (1).

الجدول (1) معدل نتائج الخصائص الفيزيائية للحجر الرملي.

\begin{tabular}{|c|c|}
\hline معدل النتائج & نوع الفحص \\
\hline 18.5 & الكثافة الجافة (kN/m3) \\
\hline 2.72 & الوزن النوعي (Gs) \\
\hline 31 & المسامية المطلقة (n\%) \\
\hline 16 & نسبة المو اد الطينية (\%) \\
\hline 44 & نسبة المو اد الغرينية (\%) \\
\hline 40 & نسبة المواد الزرملية (\%) \\
\hline 96.8 & درجة التشبع ( S\% ) عند محتوى رطوبي (16\%) \\
\hline 64.6 & درجة التشبع ( S\% ) عند محتوى رطوبي (12\%) \\
\hline 48.4 & درجة التشبع ( S\% ) عند محتوى رطوبي (8\%) \\
\hline 24.2 & درجة التشبع ( S\% ) عند محتوى رطوبي (4\%) \\
\hline
\end{tabular}

أستخدم في هذا البحث الماء المقطر لدراسة تأثير تغير المحتوى الرطوبي على على الخواص الهندسية لصخور

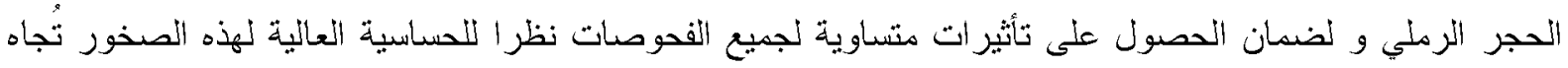

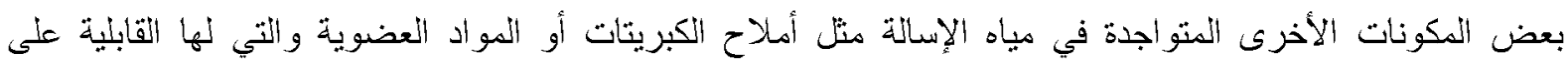

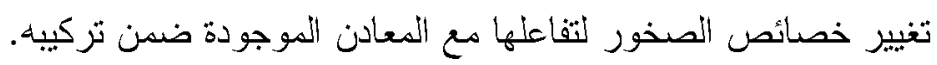

2. 2. العمل المختبري وإعداد النماذج 3. 1. نماذج فحص الانضغاط أحادي وثلاثي المحاور

4. استخر جت النماذج الاسطو انية من الكتل الصخرية بوساطة جهاز اخذ اللباب مع مر اعاة كون اتجاه محور اسطو انة اللباب عموديا على اتجاه مستويات التطبق للكتل الصخرية، وقد تم الحصول على نماذج اسطو انية بقطر

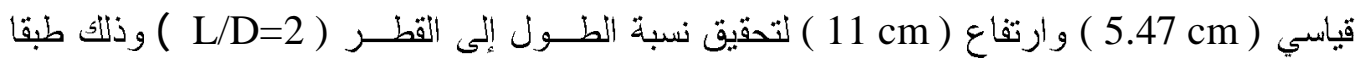

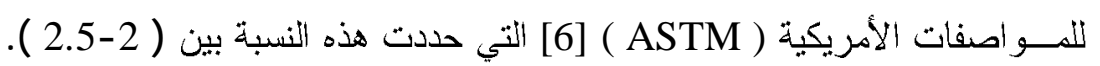




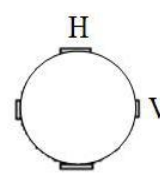

(منظر علوي)

لغرض ثياس الانفــال المحسوري ( Axial Strain ) والجانبي ( Lateral Strain ) وحساب النغير ألحجمي (لالني ) Volumetric Strain )

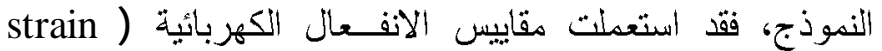

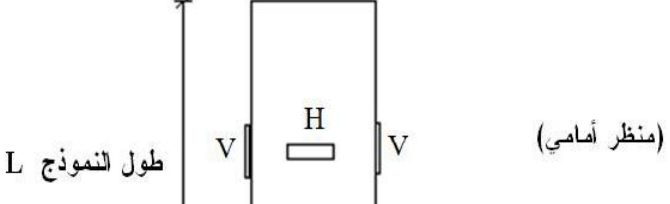

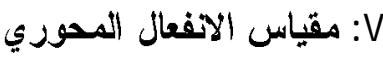

H

ألثكل (1) مخطط توضيجي يبين أماكن لصق الصق

مقلييس ألإنفهال على النماذج ألإسطو انية المية

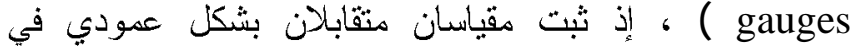

منتصف الارتفاع للنموذج ومقياسان آخران أفقيان متقابلان في

منتصف الارتفاع أيضا بموجب المواصفات العالمية الأمريكية )

[6] ASTM, 89 ) وكما موضح في الثكل (1).

2.3نماذج فَحص الاتحناء:

تم إعداد النماذج باستخدام المنشار الكهربائي إذ تثت

عملية القص بشكل مواز لمستويات تطبق الصذرة وذلك لضمان تليط الأتثال بشكل عمودي على هذه المستويات أثثاء الفحص.

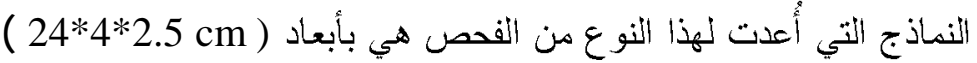

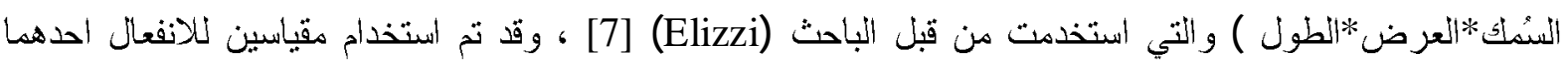

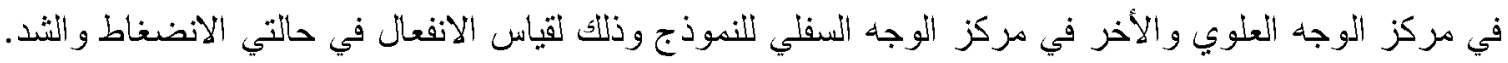

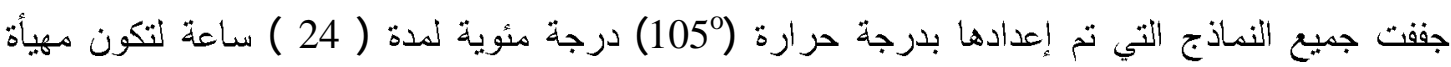

للفحوصات المطلوية.

3.3 عملية تشييع النماذج:

لغرض الحصول على نماذج ذات محتوى رطوبي متغير ( 0\%, 4\% , 8\% , 12\% , 16\% ) تم تجفيف

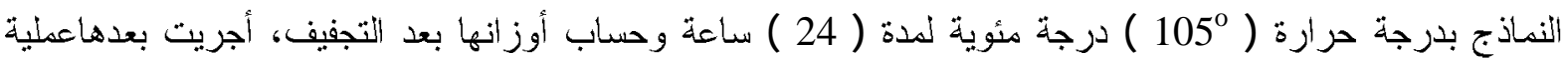

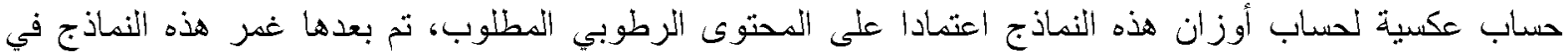

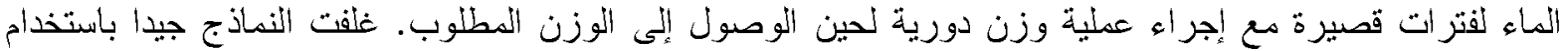

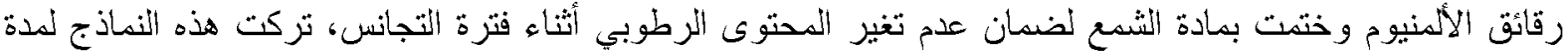

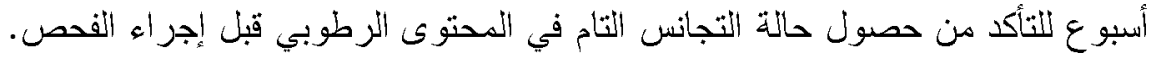

4.3 4ملية قياس الاتفعال

أُستخدم في عملية قياس الانفعال جهاز مقياس الانفعال (Strain Meter) والذذي يعمل بعد إدخال البيانات والأوامر خلال لوحة الفاتيح حيث تظهر بعدها نتائج قراءات الانفعال كل (0.2) من الثانية وتحت ثانثير أحمال مستمرة أو ثابتة، ويمكن ربط عدد من مقاييس الانفعال مع بعضها ليعطي الجهاز معدل نتائجها. 


\section{4. الفحوصات الميكانبكية}

تم إجر اء الفحوصات الميكانيكية التالية على صخور الحجر الزرملي وباستخدام نسب رطوبة مختلفة لكل

فحصن.

1.4 فحص الانضغاط أحادي ونثلثي المحاور:

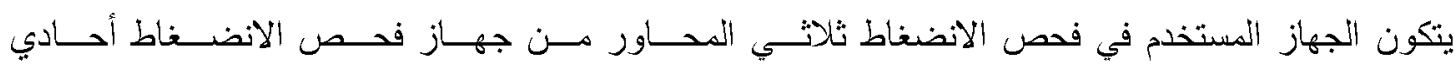

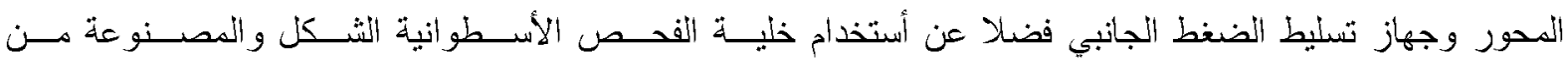

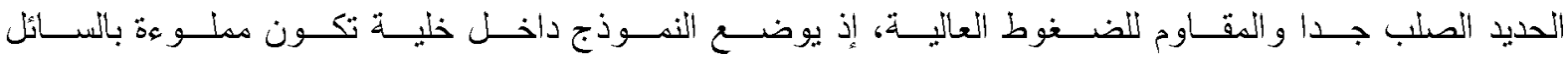

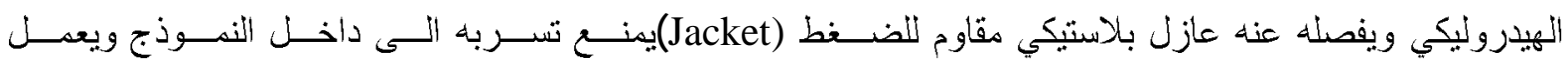

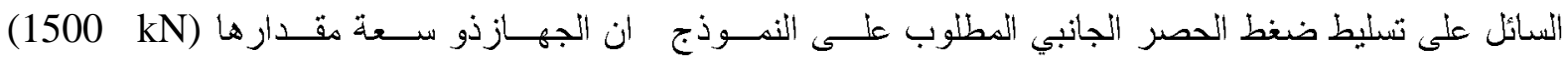

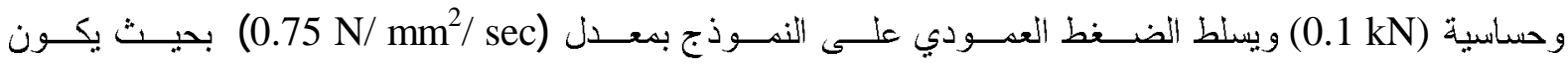

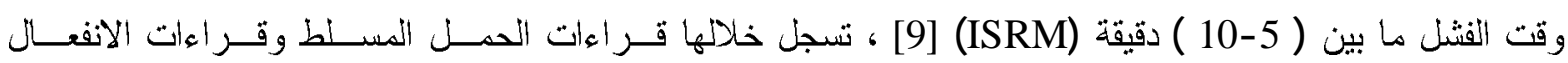

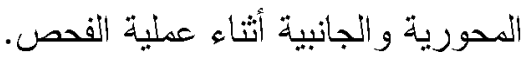
تحسب مقاومة الانضغاط أحادي المحور للنموذج باستخدام المعادلة الآتية:

$\sigma_{c}=\frac{P}{A_{f}}=\frac{P\left(1-\varepsilon_{L}\right)}{A_{o}}$

P : الحمل المؤدي إلى فشل النموذج (N). مساحة مقطع النموذج قبل الفحص (mm²) : Ao

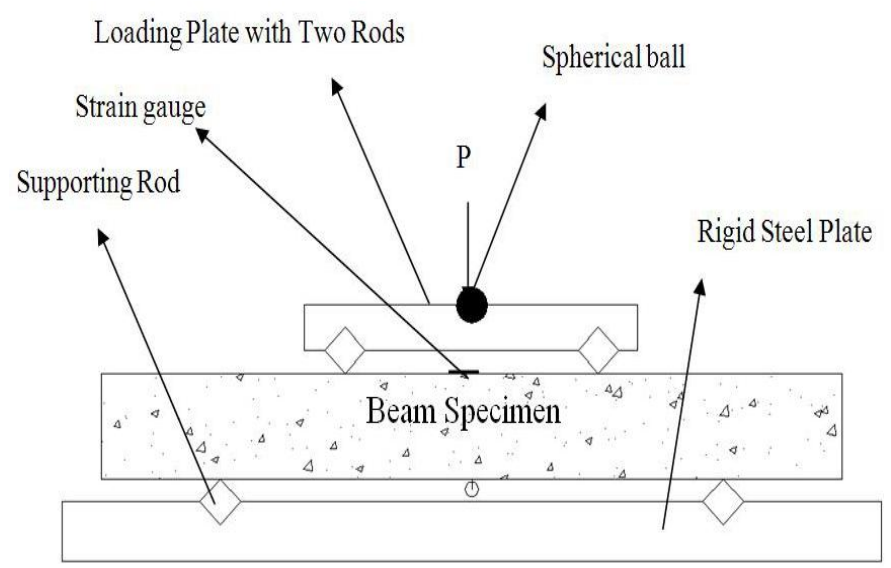

شكل (2) المخطط التوضيحي للجهاز المستخدم في فصص الأنحناء

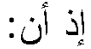

(N/ mm²) مقاو مة الاتضغناط:

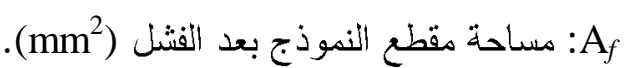
ع : الانفعال الجانبي عند الفشل(mm/mm).

\section{(2.4 فحص الانحناء:}

تم اختباز هذا الفحص لأنه بمتل فحص الانحناء احذ

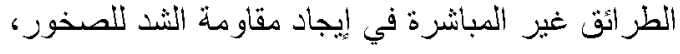

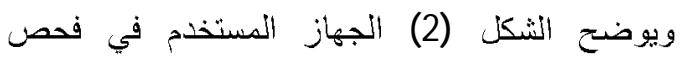
الانحناء ذات المساند الأربعة، وقد تم استخداهـــ

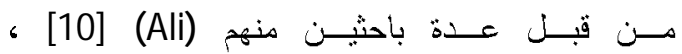
(111] (Noori)

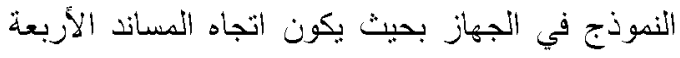
عموديا على دستوى التطبق، وتكون سزعة التحميل (ASTM) بموجب المواصفات (0.254m/min) [6] ، وقد أخذت قراءات الانفعال في حالتي الثند

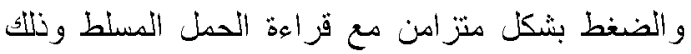


$\begin{array}{llll}\text { Al-Rafidain Engineering } & \text { Vol.19 } & \text { No.1 } & \text { February } \\ 2011\end{array}$

باستخدام جهاز قياس الانفعال (Strain M eter) ولحين الوصول إلى فشل النموذج.

تم تطبيق المعادلة التالية في إيجاد المقاومة التشدية للنماذج المشتقة من قبل الباحث (Duckworth) [13]؛

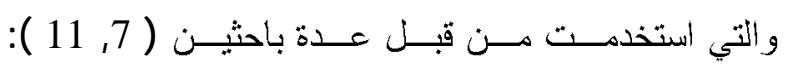

$\sigma_{t}=\frac{3 M\left(\varepsilon_{t}+\varepsilon_{c}\right)}{b d^{2} \varepsilon_{t}}$

إذ أن:

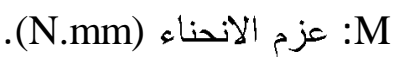

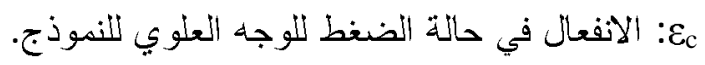

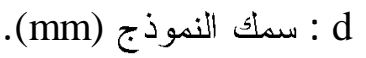

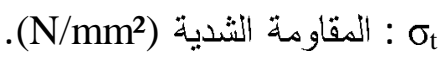
te

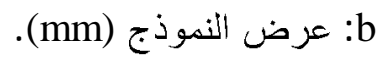

5. 5 التتائج و المناقشة 1.5

1.5 تأثير الترطيب عثى المقاومة في فحص الاتضغاط ثلاثي المحاور:

تم ايجاد مقاومة الانضغاط ثلاثي المحاور لصخور الحجر الرملي وذلك للتعرف على تأثثير تغير المحتوى الرطوبي للصخور وتغير ضغط الحصر الجنبي نها على قيم كل من إجهاد الانحر اف (

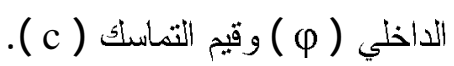

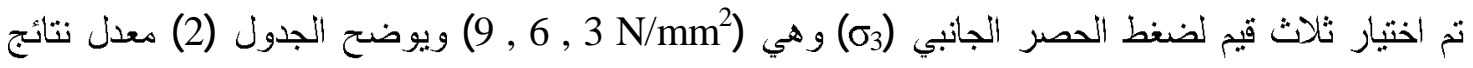

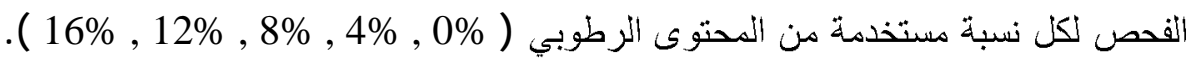
الجدول (2) معدل نتائج فحص الأضغاط ثلاثي المحاور.

\begin{tabular}{|c|c|c|c|c|}
\hline S.D* & $\begin{array}{c}\text { إجهاد الانحر افت } \\
\left(\sigma_{1}-\sigma_{3}\right)\left(N / m^{2}\right)\end{array}$ & 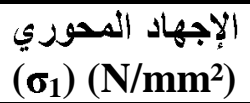 & ضغط العصر الجانبي & الرطتوي \\
\hline 0.98 & 17.39 & 20.39 & 3 & \multirow{3}{*}{$0 \%$} \\
\hline 0.87 & 20.97 & 26.97 & 6 & \\
\hline 1.13 & 25.44 & 34.44 & 9 & \\
\hline 0.54 & 11.49 & 14.49 & 3 & \multirow{3}{*}{$4 \%$} \\
\hline 0.41 & 13.06 & 19.06 & 6 & \\
\hline 0.37 & 14.46 & 23.46 & 9 & \\
\hline 0.41 & 7.31 & 10.31 & 3 & \multirow{3}{*}{$8 \%$} \\
\hline 0.30 & 7.98 & 13.98 & 6 & \\
\hline 0.21 & 8.89 & 17.89 & 9 & \\
\hline 0.27 & 6.31 & 9.31 & 3 & \multirow{3}{*}{$12 \%$} \\
\hline 0.20 & 6.78 & 12.78 & 6 & \\
\hline 0.31 & 7.21 & 16.21 & 9 & \\
\hline 0.11 & 5.11 & 8.11 & 3 & \multirow{3}{*}{$16 \%$} \\
\hline 0.17 & 5.52 & 11.52 & 6 & \\
\hline 0.23 & 6.35 & 15.35 & 9 & \\
\hline
\end{tabular}

* Standard Deviation. 
نوري: تأثير تغير المحتوق الرظويي في بعض خصائص القوة لصخور الحجر الزملي في مدينة الموصل

يلاحظ من الجدون أن مقاومة الانضغاط ثلاثي المحاور تقل بصورة كبيرة مع زيادة المحتوى الرطوبي

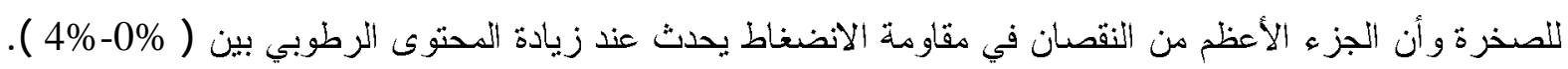
كما يلاحظ أن قيم أجهاد الانحر اف (

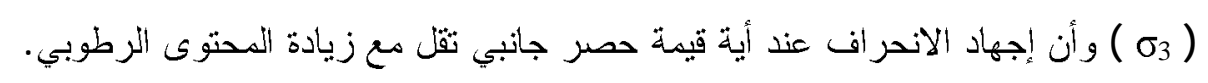

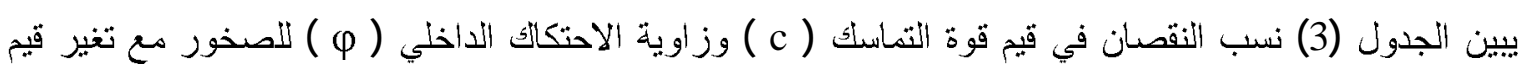

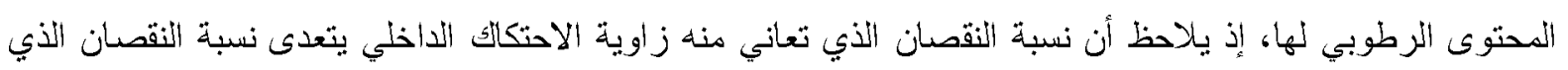

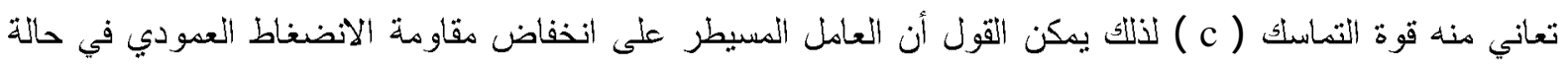

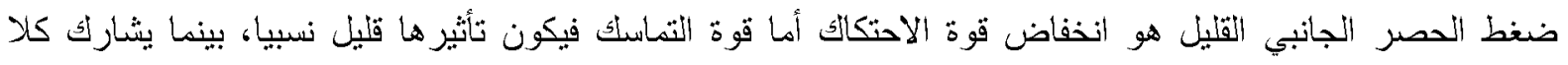
العاملين ( انخفاض قوة التماسك وانخفاض زاوية الاحتكاك الداخلي ) في حالة ضغط الحصر الجانبي العالي لان

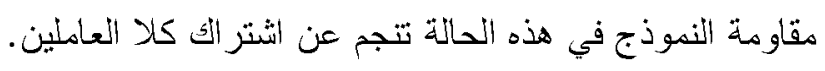

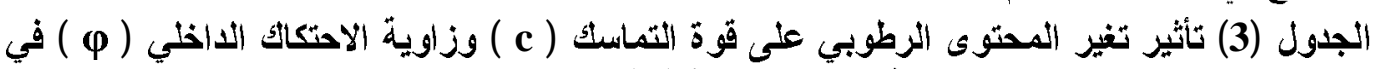
فحص الاتضغاط ثنلاثي المحاور .

\begin{tabular}{|c|c|c|c|c|}
\hline نسبة النقصان & 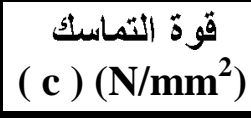 & نسبة النقصان & 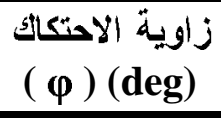 & الرطوبتي \\
\hline--- & 4.34 & -- & 24 & $0 \%$ \\
\hline 2 & 4.25 & 55 & 10.7 & $4 \%$ \\
\hline 29 & 3.07 & 76 & 5.6 & $8 \%$ \\
\hline 37 & 2.7 & 82 & 4.3 & $12 \%$ \\
\hline 48 & 2.26 & 85 & 3.4 & $16 \%$ \\
\hline
\end{tabular}

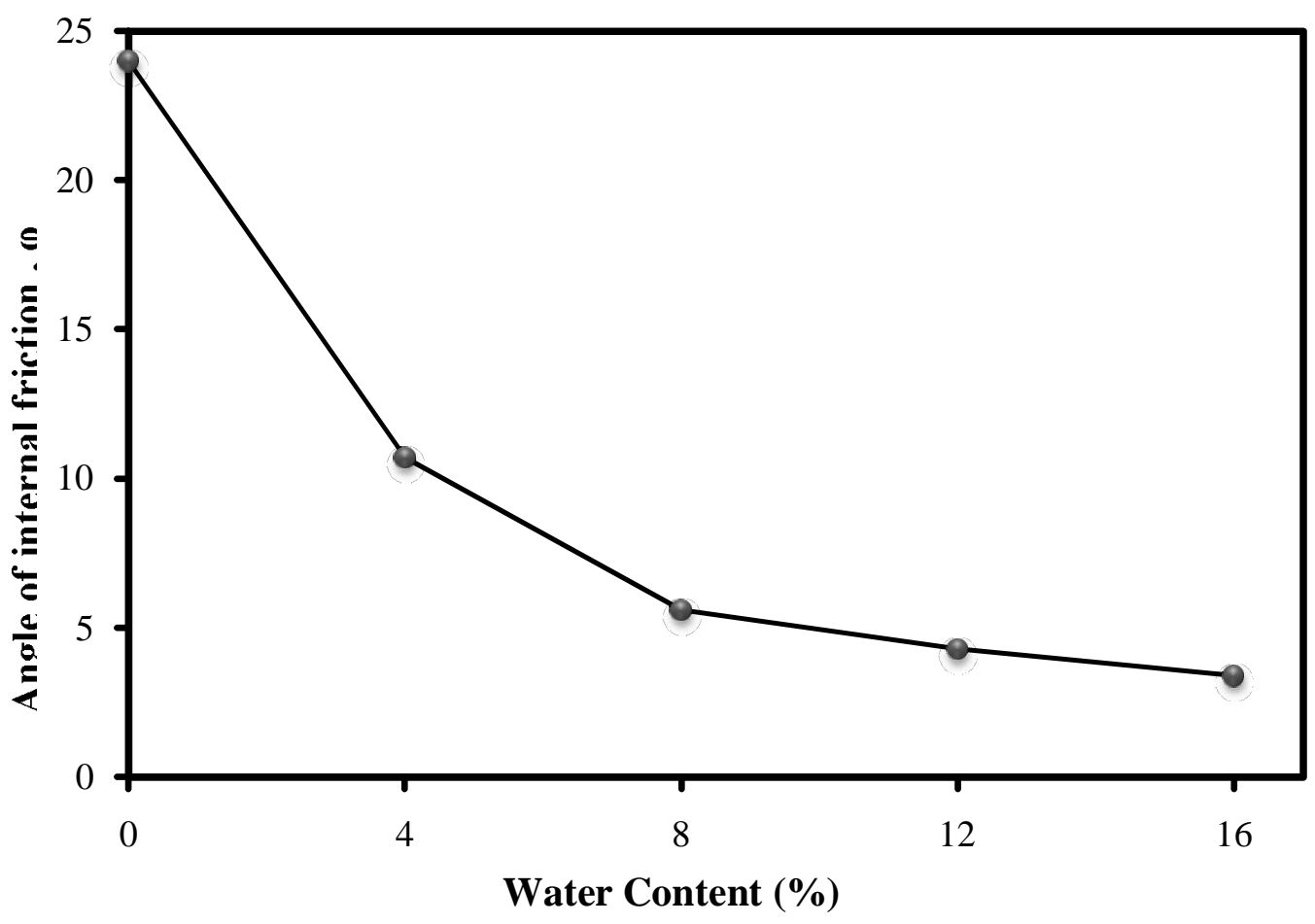

الشكل (3) تأثر زاوية الاحتكائ الأخلي بتغير المحتوى الرطوبي 


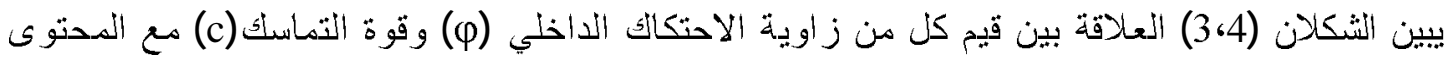
الرطوبي على التو الي، ويلاحظ حدوث تغير واضحً مع تغير المحتوى الرطوبي بين (0\%-8\% ) ليصبح التغير اقل بعد هذا المدى.

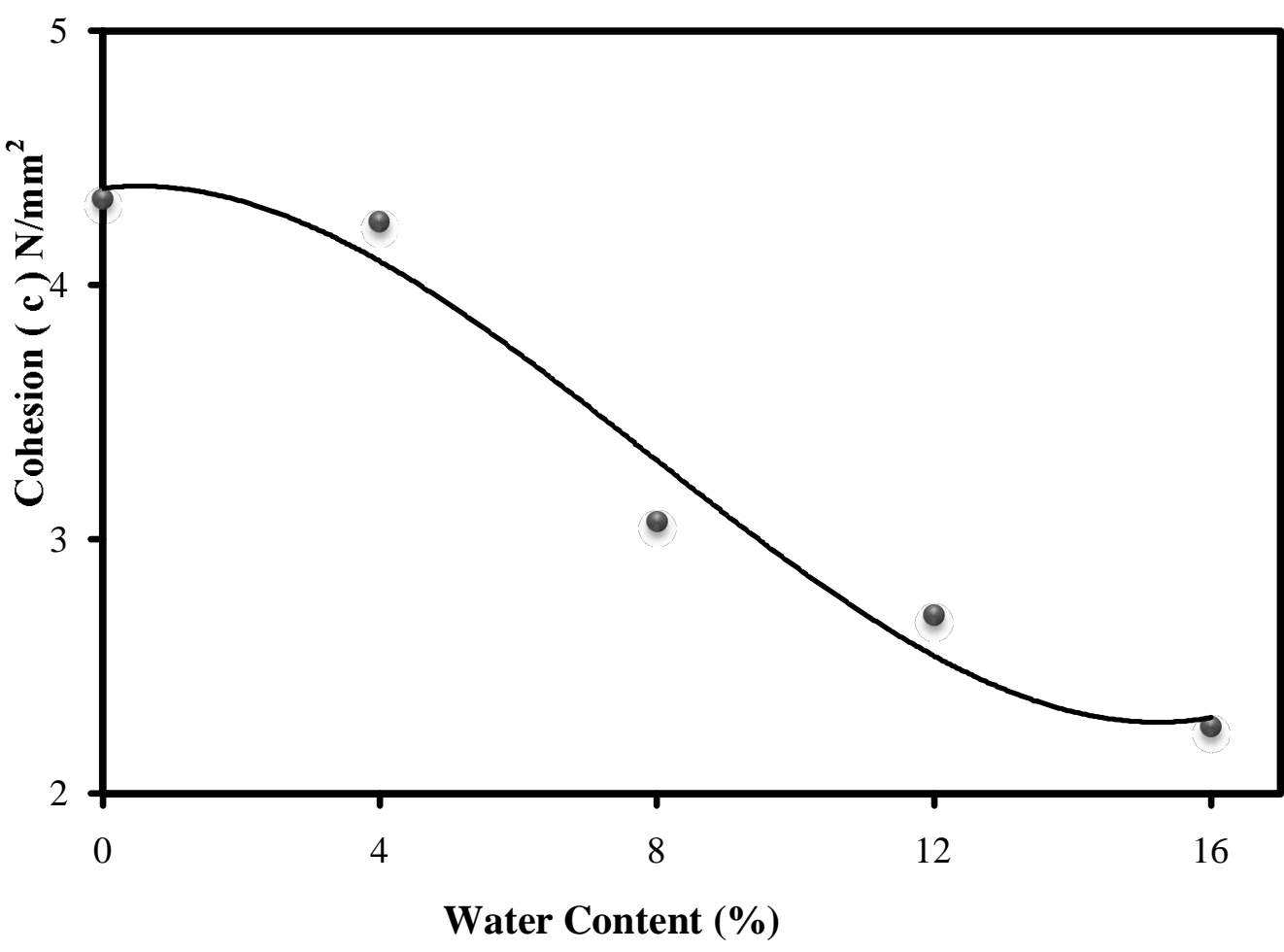

الثكل (4) تأثر قيم التماسك بتثير المحتوى الزطوبي

توضح الأشكال (5)A و (6)A و العلاقة بين الانفعال المحوري والجانبي مع الإجهاد العمودي لدالات

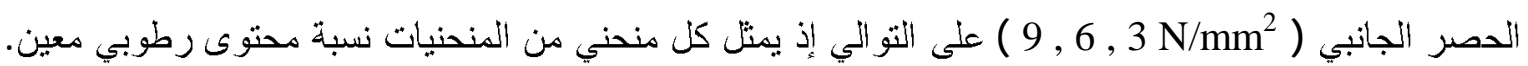

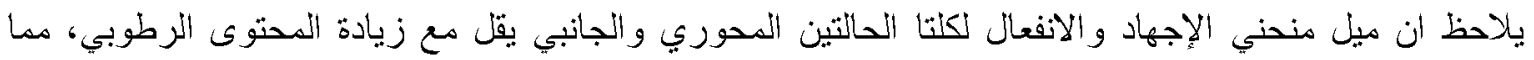
يدل على زيادة الانفعال الحاصل في النموذج عند قيمة إجهاد معينة مع زيادة المحتوى الزطوبي له، ويعزى السبب في

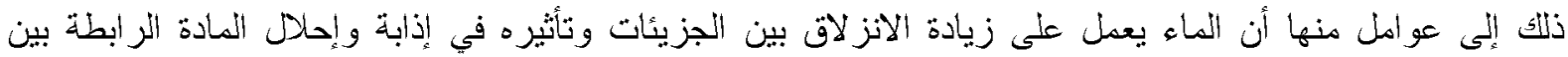
الحبيبات وبالتالي زيادة قابلية هذه الحبيبات على الحركة فوق بعضها البعض وهذا موافق لما وجده الباحثان .[15](Hawkins and Connell) [14](Kwasnieski) إن التغير في الانفعال ألحجمي مع الإجهاد المحوري موضح في الأشكال (5)B , (6)B (7)B لحالات ضغط

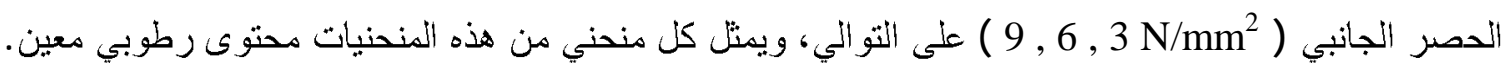

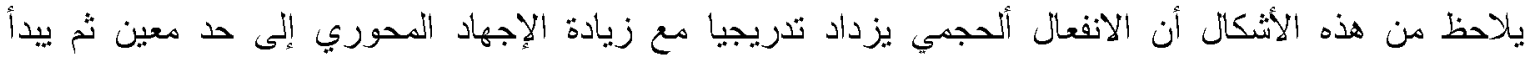
بالنقصدن إلى حد يعتمد على حالة الصخرة إذ يعود النموذج إلى حالة انفعال حجمي مقارب للصفر في الحالة الجافة، بينما لا تعود النماذج الزرطبة إلى هذه النقطة وإنما تبقى محتفظة بجزء من الانفعال ألحجمي عند حدوث الفثل بوقد لوحظ أُيضا في أثثاء الفحص أن شكل فنل النموذج يتغير من حالة الفنل الصلب Brittle) Failure ) إلى حالة الفشل اللدن ( Ductile Failure ) هع زيادة المحتوى الرطوبي. 
نوري: تأثير تفير المحتوى الرظوبي في بعض خصائص القوة لصخور الحجز الزملي في هدينة الموصل

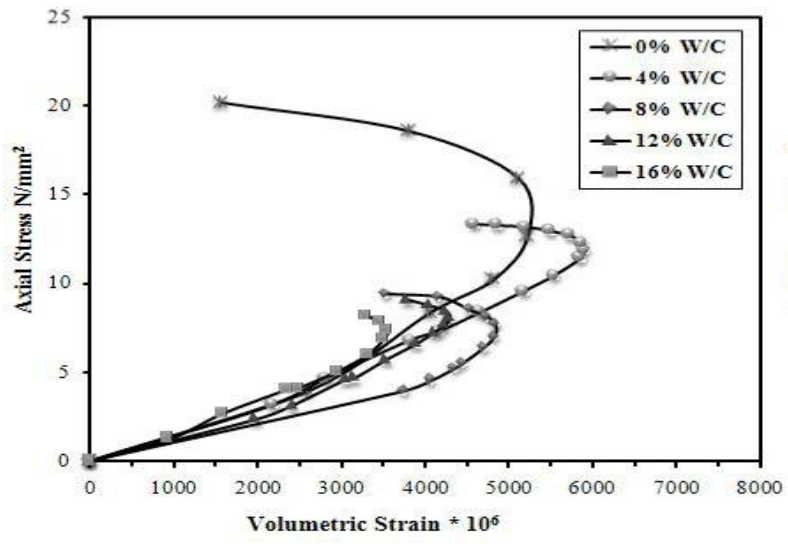

(B)

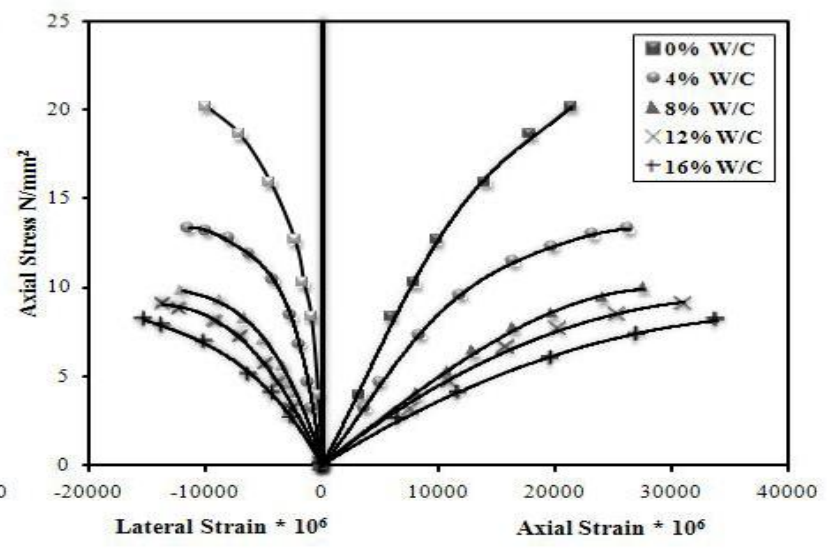

(A)

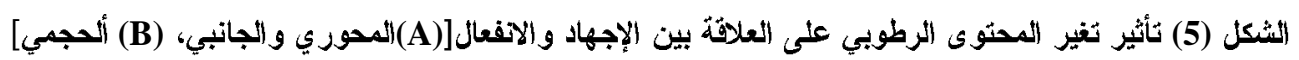

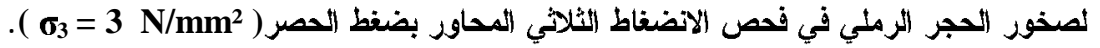

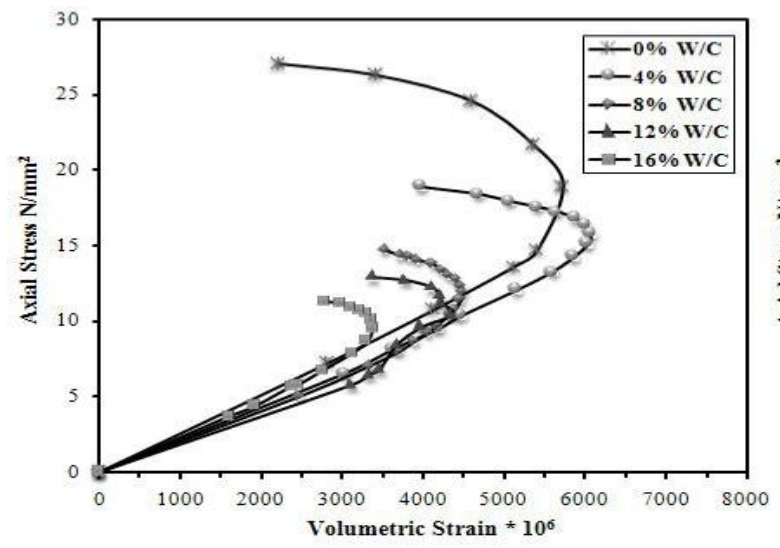

(B)

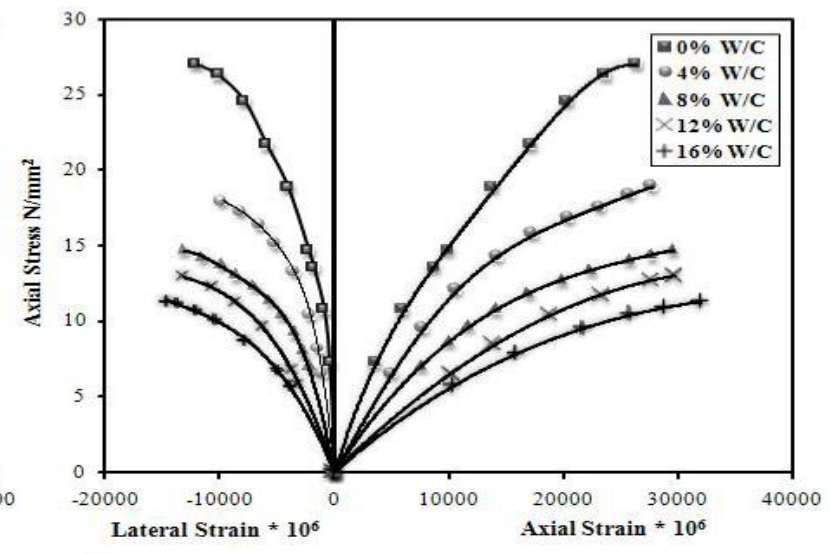

(A)

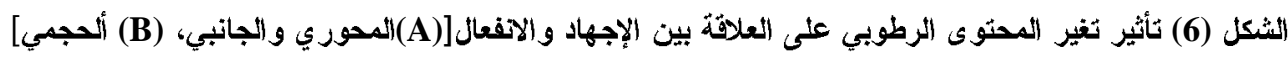

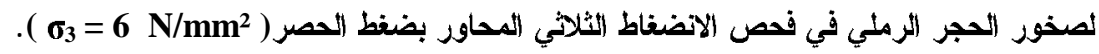

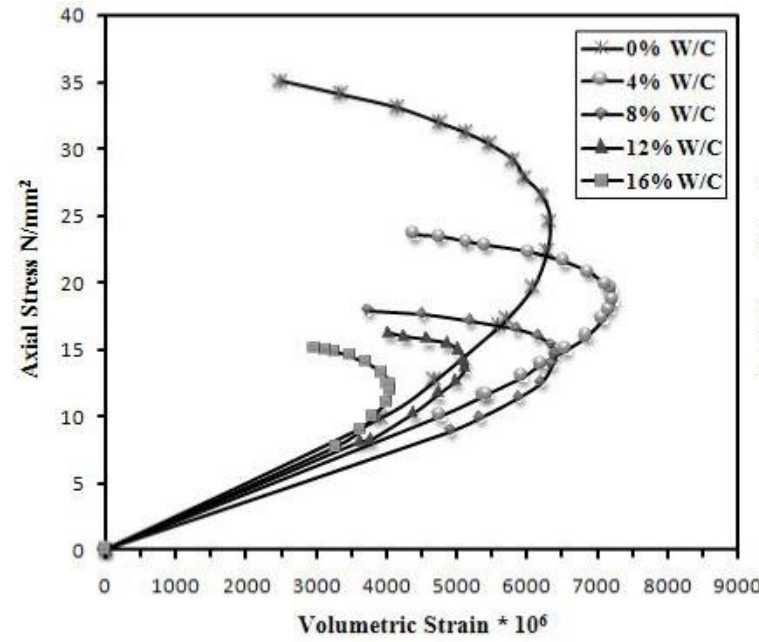

(B)

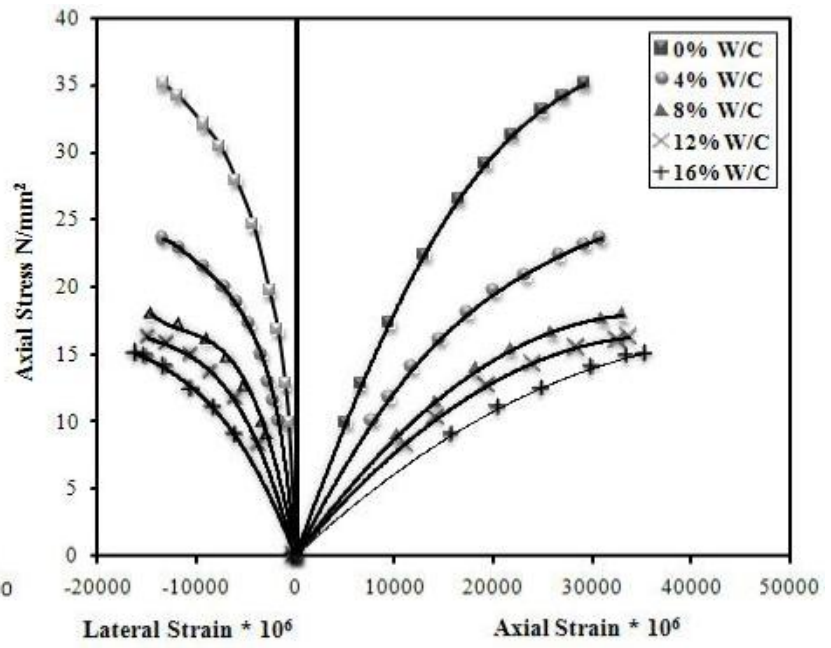

(A)

الثكل (7) تأثير تغير المحتوى الرطوبي على العلاقة بين الإجهاد والآفعال[(A)(المحوري والجانبي، (B)

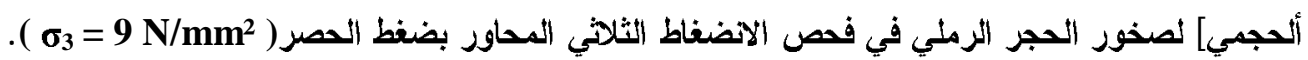




\section{5 تأثير الترطيب على مقاومة الانضغاط في فحص الانضفاط أحادي المحور :}

يبين الجدول (4) معدل نتائج القحص لأربعة نماذج لكل نسبة من نسب المحتوى الرطوبي المختلفة، كما

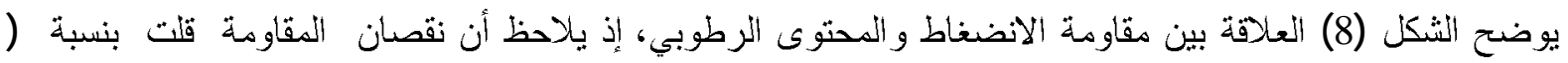
88.5\% ) بتغير المحتوى الزطوبي من ( 0\%-16\% )، كما أن ( الانضغاط أحادي المحور حدث في أثناء تغير الهحتوى الرطوبي هن( 0\%-4\% )، ويعود سبب هذا النقصان الكبيزفي

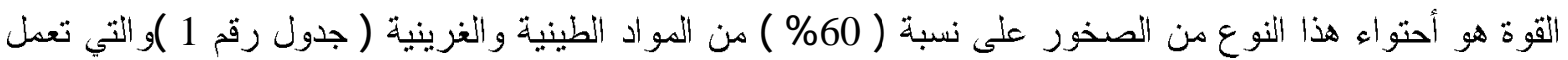

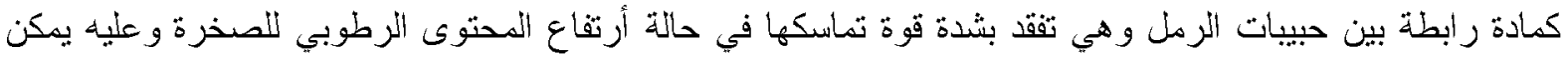

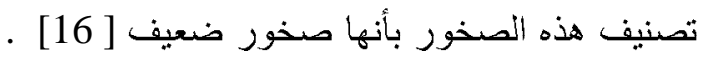

الجدول (4) معدل نتاتج فص الاتضغاط أحادي المحور في حالات الترطيب المختلفة

\begin{tabular}{|c|c|c|c|}
\hline S.D & نسبة النقصانة في المقاومة مقارنة & مقاومة الانضغاط أحادي المحور & الرطويبي \\
\hline 0.879 & --- & 9.43 & $0 \%$ \\
\hline 0.440 & 69 & 2.91 & $4 \%$ \\
\hline 0.084 & 83 & 1.57 & $8 \%$ \\
\hline 0.101 & 87 & 1.2 & $12 \%$ \\
\hline 0.136 & 88.5 & 1.08 & $16 \%$ \\
\hline
\end{tabular}

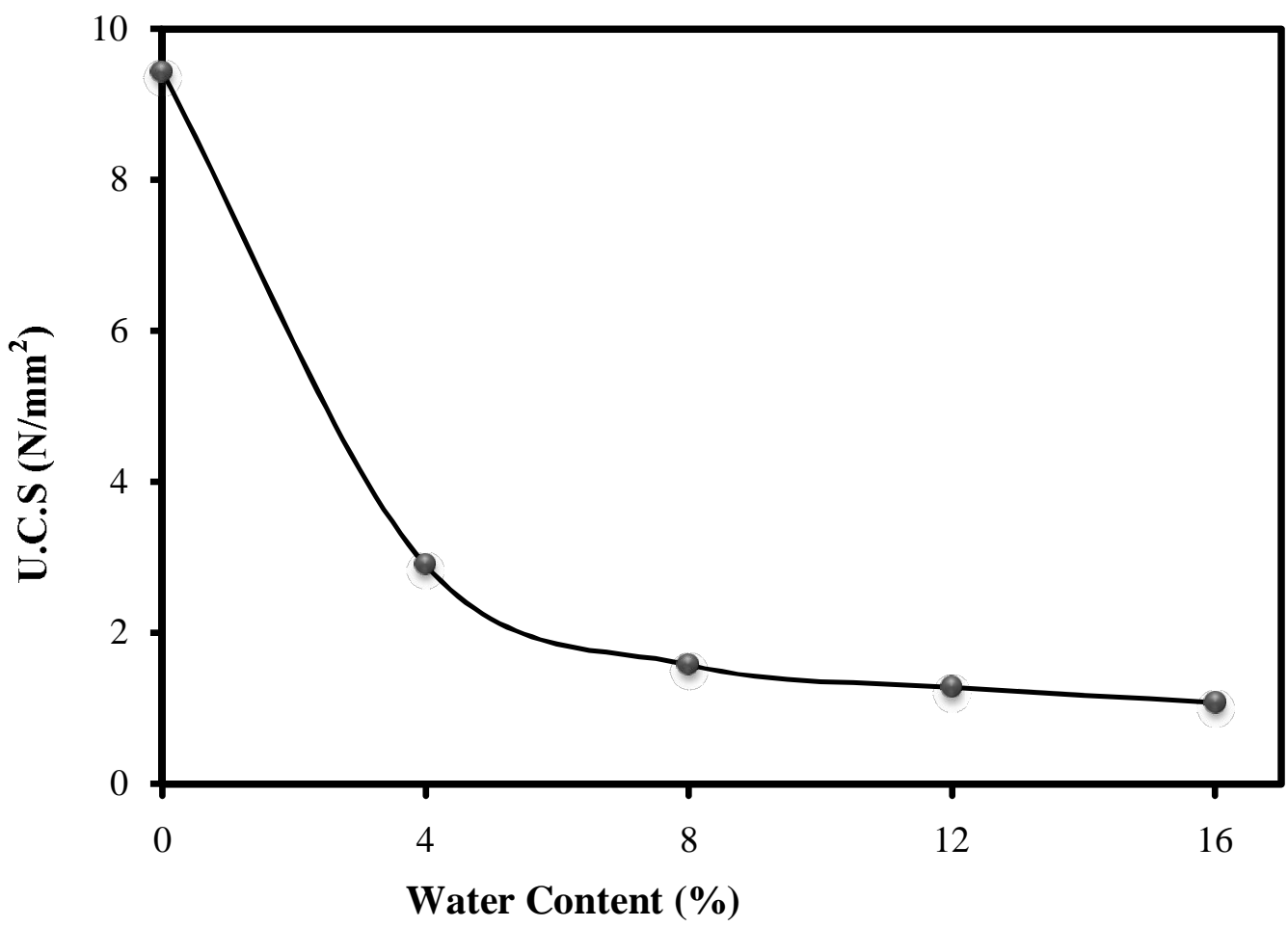

الثكل ( 8 ) العلاقة بين مقاومة الاضضغاط(U.C.S) والمحتوى الزطوبي لصخور الحجر الرملي 
ويمكن توضيح عدة أسباب لحدوث النقصان في مقاومة الانضغاط الاحادية و التنلاثية المحاورلصخور الحجر

$$
\text { الرملي نتيجة التشبع بالماء اضافة الىى الاسباب التي ذكرت في في الققرة (2.6): }
$$

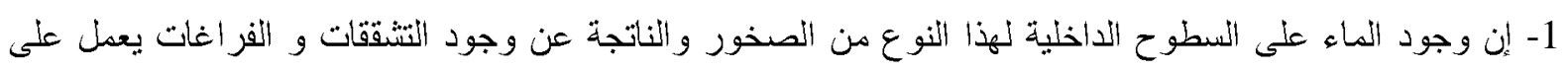

تقليل الطاقة السطحية لهذه الصخور وبالتالي إلى نقصان المقاومة] 117.

2- إن وجود الماء يعمل على تحلل المادة الرابطة بين الحبيبات و التي تؤدي إلى تكوين مناطق ضعف في الصخرة تعمل على تقليل الدقاو مة ونة.

3- يعمل الماء على تقليل هعامل الاحتكالك ( 1 ) بين حبيبات الحجر الرملي إذ أن وجود الماء يساعد الحبيبات على

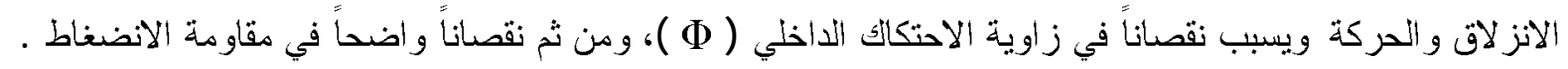

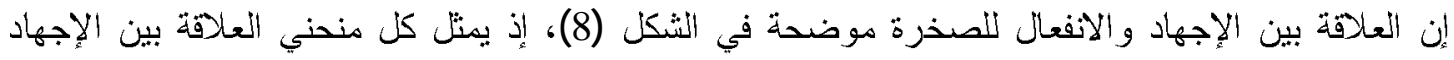
والانفعال لنسبة معينة من المحتوى الترطوبي والتي تباينت بين ( 0\%-16\% ) و اللذان يمثلان حالة الجفاف وحالة التتبع على التو الي.

ويبين الثنكل أُيضا أن ميل منحني الانفعال المحوري و الجانبي يقل بصورة واضحة مع زيادة المحتوى

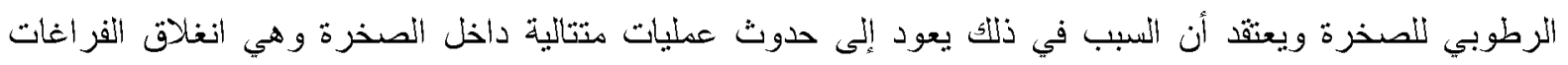

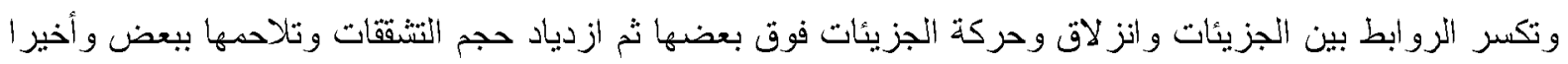

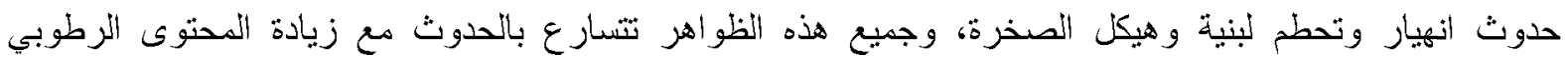
للصخرة.

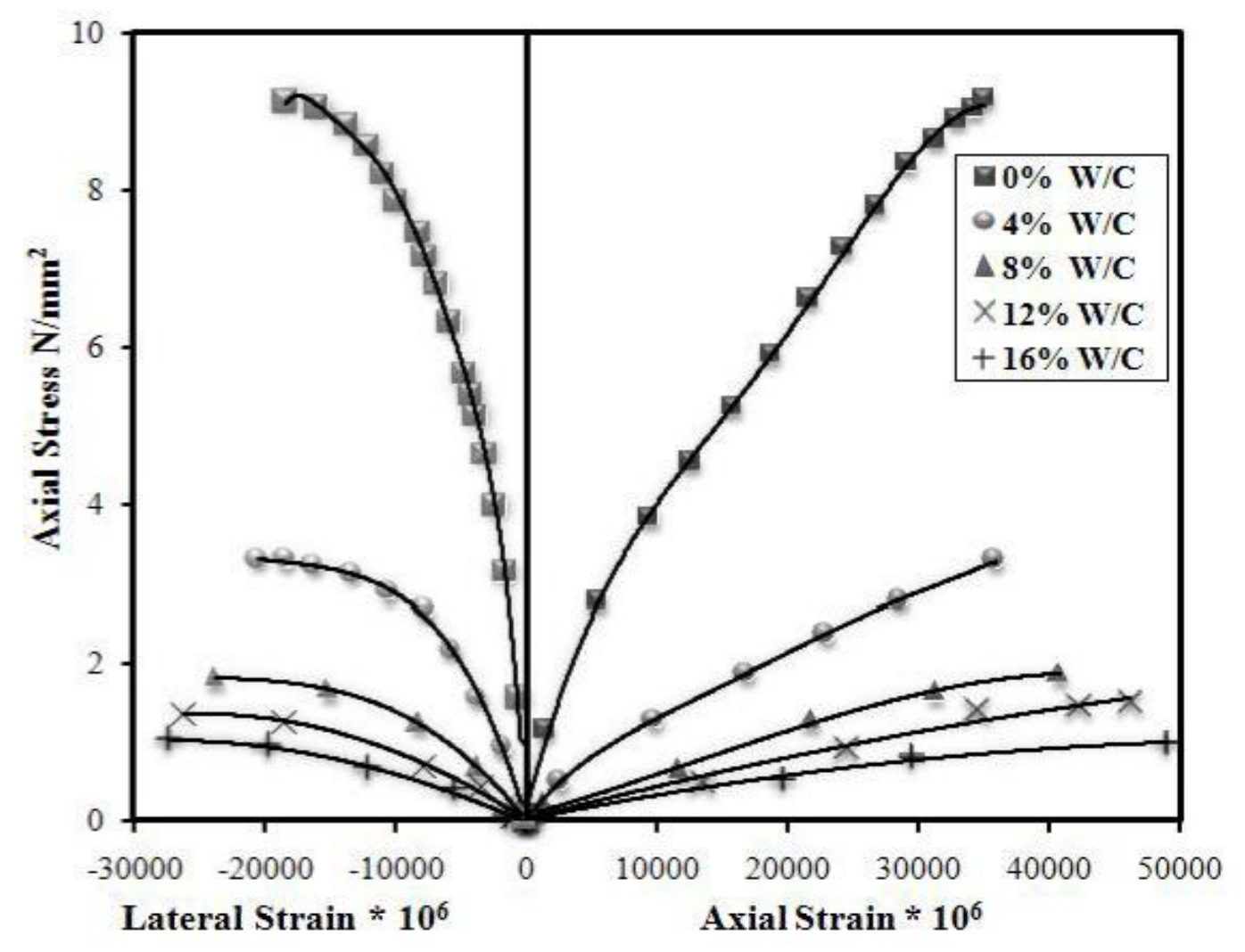

أُ لثنكل (9) تأثيُر تغير المحتوى الرطوبي على العلاقة بين الإجهاد و الانفعال[المحوري والجانبي] لصخور الحجر

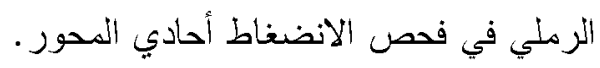


3.5 تأثير الترطيب على مقاومة الثَد في فحص الاتحناء: إن أُبعاد النماذج المستخدمة في هذا القحص هي ( ويبين الجدول (5) معدل النتائج لستة نماذج نم الحصول عليها لكل نسبة من نسب المحتوى الرطوبي ( , 16\% , 12\% 8\% , 4\% , 0\% ) وقد لوحظ أن الفنل الحاصل كان ضمن الثلث الوسطي لطول النموذج و الؤ اقعة بين المسندين الجذول (5) معدل نتائج فحص الاتحناء للنماذج بمحتوى رطوبي منغير

\begin{tabular}{|c|c|c|c|}
\hline S.D & نسبة النقصان في المقارمة بالئة الجافة (\%) & $\begin{array}{l}\text { المقاومة الشدية } \\
\text { (N/mm²) }\end{array}$ & الرطوبي المتوي \\
\hline 0.479 & --- & 2.335 & $0 \%$ \\
\hline 0.181 & 73 & 0.627 & $4 \%$ \\
\hline 0.148 & 86 & 0.331 & $8 \%$ \\
\hline 0.098 & 92 & 0.178 & $12 \%$ \\
\hline 0.079 & 94 & 0.135 & $16 \%$ \\
\hline
\end{tabular}

من خلال الجدول السابق يمكن ملاحظة تأثير تغير المحتوى الرطوبي على مقاومة التثد,إذ يعمل الماء على تقليل الكقاومة بصورة كبيرة بسبب نقليل قوة التماسك و الثتلاصق بين حبيات الصخرة و المادة الر ابطة، ويظهر تأثير

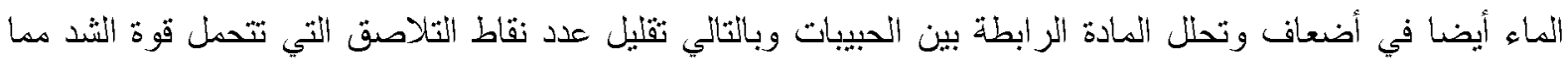

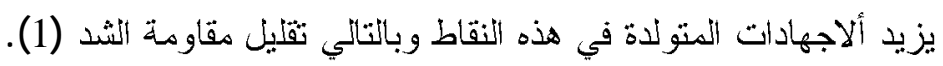

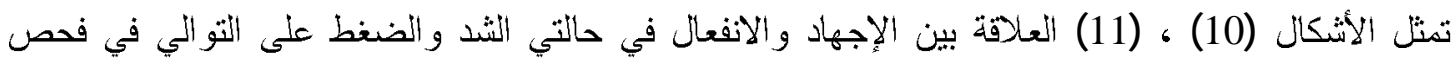
الانحناء، ونلاحظ من هذه الأشكال أن مبل منحنى الإجهاد و الانفعال يقل بزيادة المحتوى الرطوبي، كما نلاحظ النه الن ميل منحني الإجهاد والانفعال في حالة الثثد يكون اكبر من حالة الانضغاط وان هذا الاختلاف في الميل يكون اكبر ما يمكن في الحالة الجافة ويقل أو يتلاثىى مع زيادة المحتوى الرطوبي، وقد يعزى السبب في ذللك إلى أن الماء يعمل على تقليل الاختلاف في خصائص الإجهاد والانفعال بين حالتي الضغط و الثتد وبالتالتي اقتراب المحور المتعادل ( Neutral ) من المحور المركزي للجسم والذي يمر في منتصف ارتفاع النموذنج.

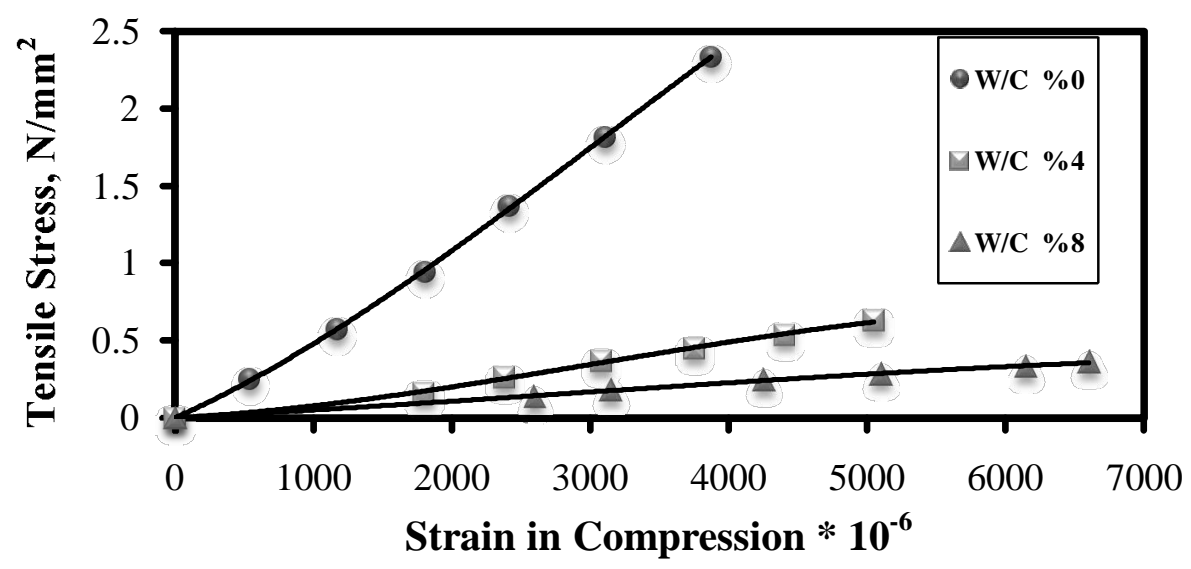

شكل (10) تأثير تغير المحتوى الزطوبي على العلآة بين الإجهاد و الآفعال في حالة

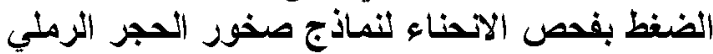




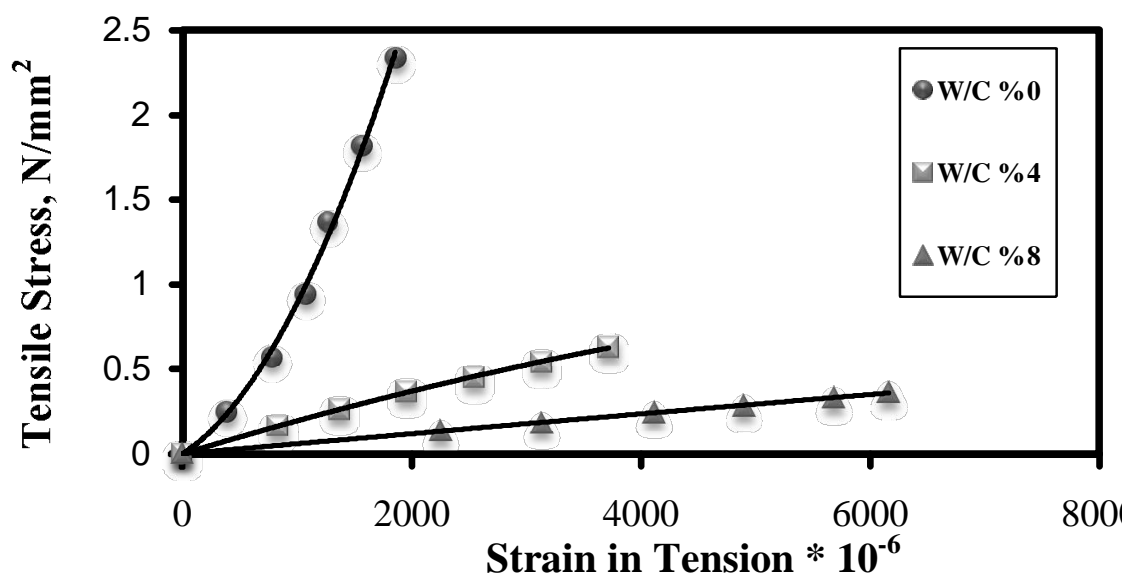

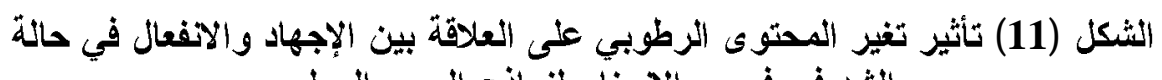

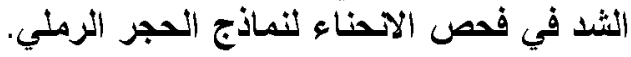

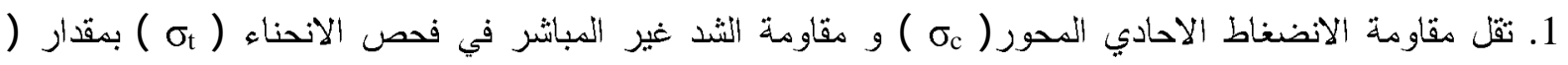
89\% - 94\% ) على التو البي وذللك عند زيادة المحتوى الرطوبي للصخرة الى الى (16\%).

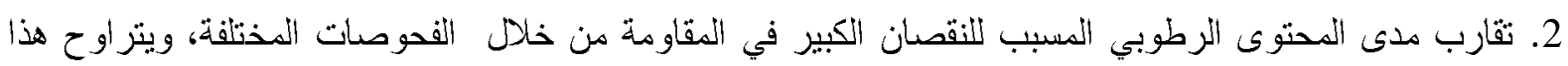

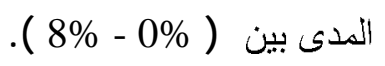

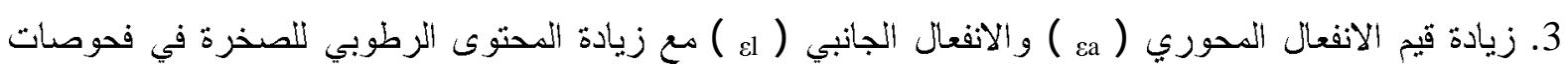

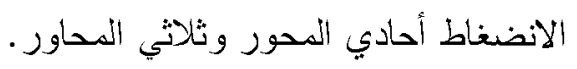

4. مقاومة الانضغاط ثلاثي المحاور تقل بصورة كبيرة مع زيادة المحتوى الرطوبي للصخرة وان الجزيء الكبير من

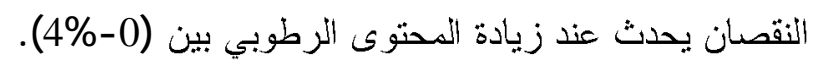

\section{References}

1- Dube, A. K., and Singh, B., (1972), " Effect of Humidity on Tensile Strength of Sandstone " J. Mines, Metals and Fuels", Vol. 20, No. 1, pp. 8-10.

2- Masuda, K., (2001), " Effects of Water on Rock Strength in a Brittle Regime ", Journal of Structural Geology, Vol. 23, pp. 1653-1657.

3- Hawkins, A. B., and McConnell, B. J., (1992), " Sensitivity of Sandstone Strength and Deformability to Changes in Moisture Content ", Quart. J. Eng. Geol., Vol. 25, pp. 115130.

4- Thabet, K. M., Khattab, S. I., and Noori, T. M., (1994),

" Geotechnical Characteristics of Mosul Marble ", Dirasat (Pure and Applied Sciences), Vol. 21B, No. 6, pp. $25-40$.

5- ISRM., (1979), " Suggested Methods for Determining Water Content, Porosity, Density, Absorption and Related Properties ", ISRM. Committee on Standardization of 
Laboratory Tests, Int. J. Rock Mech. Min. Sci., Vol. 16, pp. 143-156.

6- $\quad \operatorname{ASTM}$ (D 854-58) (D 422-63), (1989)," American Society for Testing and Materials ", Vol. 04-08.

7- Elizzi, M. A., (1976), " Time - Dependent Behaviour of Some Evaporate Rocks ", Ph.D. Thesis, University of Sheffield. U.K

8- Franklin, J. A. and Hoeck, E., (1970), " Developments in Triaxial Testing Technique " Rock Mechanics, Vol. 2, pp. 223-228.

9- ISRM., (1979), " Suggested Methods for Determining the Uniaxial Compressive Strength and Deformability of Rock Materials ", ISRM. Committee on Standardization of Laboratory Tests, Int. J. Rock Mech. Min. Sci., Vol. 16, pp. 137-140.

10- Ali, S.A.and Noori, Th.M.,( 1998 )." Effect of oils on the strength and deformation Properties of Limestone " , Proc. Of the sixth Sci,Conference for Foundation Tech. Institutes,Baghdad-Iraq, pp.226-232

11- Noori, T. M., (1989), " Study of the Long - Term Strength of Gypsum ", M.Sc. Thesis, Civil Engg. Dept., College of Engineering, University of Mosul.

12- AL-Mahdawi, S. K., (1985). " Effect of Specimen Sizes and Water Saturation on Strength Properties of Jeribe Limestone ", M.Sc. Thesis, Civil Engg. Dept., College of Engineering, University of Mosul.

13- Duckworth, W. H., (1951), " Precise Tensile Properties of Ceramic Body ", J. Amer. Cer. Soc., Vol. 34, No. 1, pp. 1 - 9.

14- Kwasniewski, M., (1990), " Effect of Moisture of the Mode of Deformation and Failure of Coal Measure Mudstone Under Triaxial Compression ", Strata Control in Deep Mines, Rotterdam, pp. 169 - 186.

15- Hawkins, A. B., and McConnell, B. J., (1992), " Sensitivity of Sandstone Strength and Deformability to Changes in Moisture Content ", Quart. J. Eng. Geol., Vol. 25, pp. 115130.

16- Bieniawski , Z.T., (1974 )," Geomechanics Classification of Rock Masses and its Application in Tunneling", Proceedings of the $3^{\text {rd }}$ International Congress on Rock Mechanics, Denver,pp.27-32.

17- Vutukuri, V. S., (1974), " The Effect of The Liquids on the Tensile Strength of Limestone ", Int. J. Rock Mech. Min. Sci., Vol. 11, pp 27-29.

18- Hellmann, R., Renders, P. J., Gratier, J., and Guiguet, R., (2002), " "Experimental Pressure Solution Compaction of Chalk in Aqueous Solutions, Part 1. Deformation Behavior and Chemistry ", The Geochemical Society, Special Publication, No. 7.

\section{تم اجراء البحث في كلية الهندسة - جامعة الموصل}

